\title{
Assessing Power System Stability Following Load Changes and Considering Uncertainty
}

\author{
Van Duong Ngo \\ University of Danang \\ Danang, Vietnam \\ nvduong@ac.udn.vn
}

\author{
Van Kien Pham \\ Faculty of Electrical \\ Engineering \\ The University of \\ Danang-University of \\ Science and \\ Technology, Vietnam \\ pvkien@dut.udn.vn
}

\author{
Dinh Duong Le \\ Faculty of Electrical \\ Engineering \\ The University of \\ Danang-University of \\ Science and \\ Technology, Vietnam \\ ldduong@dut.udn.vn
}

\author{
Kim Hung Le \\ Faculty of Electrical \\ Engineering \\ The University of \\ Danang-University of \\ Science and \\ Technology, Vietnam \\ lekimhung@dut.udn.vn
}

\author{
Van Ky Huynh \\ University of Danang \\ Danang, Vietnam \\ hvky@ac.udn.vn
}

\begin{abstract}
An increase in load capacity during the operation of a power system usually causes voltage drop and leads to system instability, so it is necessary to monitor the effect of load changes. This article presents a method of assessing the power system stability according to the load node capacity considering uncertainty factors in the system. The proposed approach can be applied to large-scale power systems for voltage stability assessment in real-time.
\end{abstract}

Keywords-stability; power system; power plane; uncertainty; Gaussian elimination

\section{INTRODUCTION}

Power system stability could be defined as "the ability of an electric power system, for a given initially operating condition, to regain a state of operating equilibrium after being subjected to a physical disturbance with most system variables bounded, so that practically the entire system remains intact" [1]. In [1], power system stability is broadly classified into three groups: frequency stability [2-4], rotor angle stability [5-7], and voltage stability [8-14]. Voltage stability could be defined as the ability of the system to maintain steady voltages at all buses in the system after being subjected to a disturbance from a given initial operating condition $[1,8,11]$. Voltage stability is divided into two subcategories: large and small disturbance stability. System faults, tripping transmission lines or dropping in generators are considered large disturbances whereas load changes are considered small disturbances. Static voltage stability is considered in the present paper in particular. The system is assumed to be operated in an equilibrium state and static voltage stability analysis assesses the feasibility of the operating point to provide the system operators with a permissible region in which the system can operate normally. Many techniques have been used in static voltage stability analysis in the literature. The well-known P-V and Q-V curves are widely used $[8,15-20]$ to determine the maximum permissible loading of the system. In particular, a P-V curve provides the relationship between the real power load and bus voltage and it is depicted with a constant power factor [17].
Contrariwise, a Q-V curve, plotted for a constant power [17], gives the change of bus voltages with respect to reactive power injection or absorption. Procedures for constructing both $\mathrm{P}-\mathrm{V}$ and $\mathrm{Q}-\mathrm{V}$ curves are time-consuming because a large number of power flows is needed to be executed using conventional methods and models [21]. Due to this drawback, they are not suitable to be used for online analysis. Moreover, they could be used only for certain increasing modes and not for providing the whole view of the analysis. Generally, they examine an individual bus by stressing the considered bus independently so they are not able to fully reflect the real stability condition of the system. In fact, voltage collapse occurs when the system load, i.e., real power and/or reactive power load, grows over a certain limit. Hence, voltage stability boundary needs to be plotted on a power plane [17]. It will form a P-Q curve $[8,22-26]$ that is very useful to determine boundary and operating regions for the system. Once the boundary is determined, the distance from the operating point to the voltage collape of the system can be directly assessed. For this work, stability reserve ratios are widely used in practice. Figure 1 shows, as an example, a P-Q curve (stability boundary) that divides power plane into two regions: normal region and impossible operating region. From Figure 1, stability reserve ratios $k_{P}$ and $k_{Q}$ can be calculated as follows:

$$
\begin{aligned}
& k_{P}=\frac{P_{\text {lim }}-P_{0}}{P_{0}} 100 \% \\
& k_{Q}=\frac{Q_{\text {lim }}-Q_{0}}{Q_{0}} 100 \%
\end{aligned}
$$

where, $P_{0}$ and $Q_{0}$ are real and reactive power of the considered load at the operating point; $P_{\text {lim }}$ and $Q_{\text {lim }}$ are the limitations of real and reactive power, recpectively. A P-Q curve can be determined by various approaches. In [8, 22-24], the curve is characterized by a parabolic equation, while it is assumed to follow a circle in [25]. Nevertheless, such assumptions on the shape of the curve make it unrealistic. In addition, those techniques usually require high computational time so they are not suitable for online voltage stability 
assessment. In [26], P-Q curve can be fastly constructed pointby-point without using any assumption about the shape of the curve. However, all of the above mentioned approaches are not accounted for sources of uncertainty in power systems, such as loads, uncertainties from renewable sources and random outages of branches and generating units.

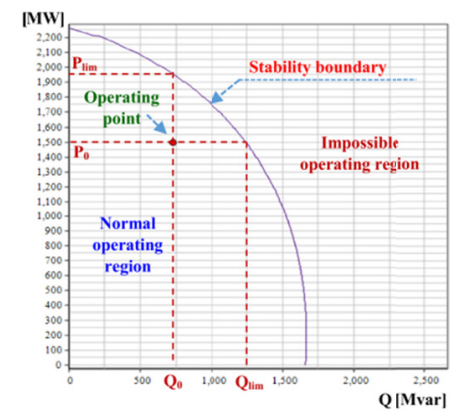

Fig. 1. P-Q curve and operating regions on power plane.

In this paper, we propose an approach to assess voltage stability considering uncertainties in power systems with a number of attractive features. Firstly, for working in a real-time environment, we adopt Gaussian elimination technique to simplify a complex diagram to a simple one, then we use the analytical technique developed in [26] for constructing P-Q curves. Thanks to these techniques, the proposed method can provide results quickly, hence it can be applied to large-scale power systems for voltage stability assessment in real-time. Secondly, in order to take into account randomness in the system, a large number of $\mathrm{P}-\mathrm{Q}$ curves is plotted and voltage stability is assessed probabilistically. In addition, the P-Q curves built are realistic, since no assumption on the change of load is used to construct the curves.

\section{SIMPLIFIED POWER SYSTEM DIAGRAM ALGORITHM}

Considering a power network with $\mathrm{N}+1$ buses (including a grounding bus, denoted 0 ) in which generation buses are numbered from 1 to $\mathrm{F}$, loads are represented by admittances so remaining buses are intermediate buses, we can form admittance equations to present steady-state of the system as in (1).

$$
\left\{\begin{array}{cccccccccc}
+\dot{\mathrm{Y}}_{11} \dot{\mathrm{V}}_{1} & -\dot{\mathrm{Y}}_{12} \dot{\mathrm{V}}_{2} & \ldots & -\dot{\mathrm{Y}}_{1 \mathrm{~F}} \dot{\mathrm{V}}_{\mathrm{F}} & \ldots & -\dot{\mathrm{Y}}_{1 \mathrm{i}} \dot{\mathrm{V}}_{\mathrm{i}} & \ldots & -\dot{\mathrm{Y}}_{1 \mathrm{~N}} \dot{\mathrm{V}}_{\mathrm{N}} & = & \mathrm{J}_{1} \\
-\dot{\mathrm{Y}}_{21} \dot{\mathrm{V}}_{1} & +\dot{\mathrm{Y}}_{22} \dot{\mathrm{V}}_{2} & \ldots & -\dot{\mathrm{Y}}_{11} \dot{\mathrm{V}}_{\mathrm{F}} & \ldots & -\dot{\mathrm{Y}}_{2 \mathrm{~V}} \dot{\mathrm{V}}_{\mathrm{i}} & \ldots & -\dot{\mathrm{Y}}_{2 \mathrm{~N}} \dot{\mathrm{V}}_{\mathrm{N}} & = & \mathrm{J}_{2} \\
\ldots & \ldots & \ldots & \ldots & \ldots & \ldots & \ldots & \ldots & \ldots & \ldots \\
-\dot{\mathrm{Y}}_{\mathrm{F} 1} \dot{\mathrm{V}}_{1} & -\dot{\mathrm{Y}}_{\mathrm{F} 2} \dot{\mathrm{V}}_{2} & \ldots & +\dot{\mathrm{Y}}_{\mathrm{FF}} \dot{\mathrm{V}}_{\mathrm{F}} & \ldots & -\dot{\mathrm{Y}}_{\mathrm{Fi}} \dot{\mathrm{V}}_{\mathrm{i}} & \ldots & -\dot{\mathrm{Y}}_{\mathrm{FN}} \dot{\mathrm{V}}_{\mathrm{N}} & = & \mathrm{J}_{\mathrm{F}} \\
\ldots & \ldots & \ldots & \ldots & \ldots & \ldots & \ldots & \ldots & \ldots & \ldots \\
-\dot{\mathrm{Y}}_{\mathrm{i} 1} \dot{\mathrm{V}}_{1} & -\dot{\mathrm{Y}}_{\mathrm{i} 2} \dot{\mathrm{V}}_{2} & \ldots & -\dot{\mathrm{Y}}_{\mathrm{iF}} \dot{\mathrm{V}}_{\mathrm{F}} & \ldots & +\dot{\mathrm{Y}}_{\mathrm{ii}} \dot{\mathrm{V}}_{\mathrm{i}} & \ldots & -\dot{\mathrm{Y}}_{\mathrm{iN}} \dot{\mathrm{V}}_{\mathrm{N}} & = & 0 \\
\ldots & \ldots & \ldots & \ldots & \ldots & \ldots & \ldots & \ldots & \ldots & \ldots \\
-\dot{\mathrm{Y}}_{\mathrm{N} 1} \dot{\mathrm{V}}_{1} & -\dot{\mathrm{Y}}_{\mathrm{N} 2} \dot{\mathrm{V}}_{2} & \ldots & -\dot{\mathrm{Y}}_{\mathrm{NF}} \dot{\mathrm{V}}_{\mathrm{F}} & \ldots & -\dot{\mathrm{Y}}_{\mathrm{Ni}} \dot{\mathrm{V}}_{\mathrm{i}} & \ldots & +\dot{\mathrm{Y}}_{\mathrm{NN}} \dot{\mathrm{V}}_{\mathrm{N}} & = & 0
\end{array}\right.
$$

where:

$$
\dot{Y}_{\mathrm{ii}}=\sum_{\substack{i=1 \\ i \neq j}}^{N} \frac{1}{\dot{Z}_{\mathrm{ij}}}: \mathrm{Y}_{\mathrm{ii}}=\sum_{\mathrm{i}=0}^{\mathrm{n}} \frac{1}{\mathrm{Z}_{\mathrm{ij}}} \text { self admittance }\left(\dot{Z}_{i j}=R_{i j}+j X_{i j}\right.
$$

is the impedance of branch between $i$ and $j ; i=1 \div \mathrm{N} ; j=1 \div \mathrm{N}$ ),
$\dot{Y}_{\mathrm{ij}}=\frac{1}{\dot{\mathrm{Z}}_{\mathrm{ij}}}: \mathrm{Y}_{\mathrm{ij}}=\frac{1}{\mathrm{Z}_{\mathrm{ij}}}$ mutual admittance between bus $i$ and bus $j$.

From (1), adopting Gaussian elimination method, we can make a simplified equivalent diagram for the network as follows.

First, devide both sides of the last equation in (1) by $\dot{Y}_{\mathrm{NN}}$

$$
-\frac{\dot{Y}_{N 1}}{\dot{Y}_{N N}} \dot{V}_{1} \ldots-\frac{\dot{Y}_{N F}}{\dot{Y}_{N N}} \dot{V}_{F} \ldots \frac{\dot{Y}_{N i}}{\dot{Y}_{N N}} \dot{V}_{i} \ldots+\dot{V}_{N}=0
$$

Next, multiply both sides of each equation in (2) with $\dot{Y}_{\text {iN }}$

$$
\frac{\dot{Y}_{N I}}{\dot{Y}_{N N}} \dot{Y}_{i N} \dot{V}_{l} \ldots-\frac{\dot{Y}_{N F}}{\dot{Y}_{N N}} \dot{Y}_{i N} \dot{V}_{F} \ldots \frac{\dot{Y}_{N i}}{\dot{Y}_{N N}} \dot{Y}_{i N} \dot{V}_{i} \ldots+\dot{Y}_{i N} \dot{V}_{N}=0
$$

Eventually, subtract (3) from the $i^{\text {th }}$ equation in (2) yields

$$
\dot{Y}_{i F}^{*}=\dot{Y}_{i F}-\frac{\dot{Y}_{N F} \dot{Y}_{i N}}{\dot{Y}_{N N}}
$$

and the $\mathrm{N}^{\text {th }}$ component in each equation in (2) (i.e., $\dot{\mathrm{Y}}_{\mathrm{iN}} \cdot \dot{\mathrm{V}}_{\mathrm{N}}$ ) will be eliminated.

After the above steps, we can eliminate one equation in (1), i.e., the last equation in (1). Equation (4) is used to calculate admittances for the equivalent network after eliminating the last bus. We repeat the above process untill obtaining $\mathrm{F}+1$ equations from the initial $\mathrm{N}$ equations in (1). Therefore, we can make an equivalent network for the considered network with $\mathrm{F}$ generation buses and a load bus considered as shown in Figure 2 .

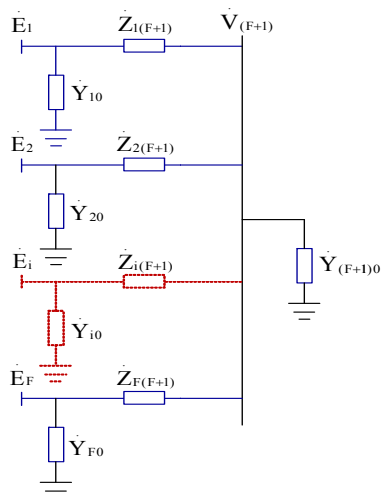

Fig. 2. Equivalent network with $\mathrm{F}$ generation buses and a load bus considered.

In Figure 2, admittance $\dot{\mathrm{Y}}_{(\mathrm{F}+1) 0}$ between bus $\mathrm{F}+1$ and the grounding bus 0 included admittance of the load at bus $\mathrm{F}+1$. In order to assess the ability according to change at the considered load, electromotive force $\dot{\mathrm{E}}_{\mathrm{i}}(i=1 \div \mathrm{F})$ is considerd as constant 
(so $\dot{\mathrm{Y}}_{\mathrm{i} 0}$ can be eliminated) and the load is separated as in Figure 3.

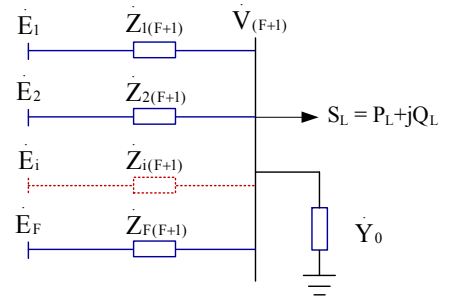

Fig. 3. Simplified equivalent diagram.

In Figure $3, \dot{Y}_{0}=G_{0}+j B_{0}$ is parallel with the admittance of the load $\dot{Y}_{\mathrm{L}}=\mathrm{G}_{\mathrm{L}}+\mathrm{jB}$, where

$$
\begin{aligned}
& \mathrm{G}_{0}=\mathrm{G}_{(\mathrm{F}+1) 0}-\mathrm{G}_{\mathrm{L}} \\
& \mathrm{B}_{0}=\mathrm{B}_{(\mathrm{F}+1) 0}-\mathrm{B}_{\mathrm{L}} \mathrm{G}_{\mathrm{L}}=\mathrm{P}_{\mathrm{L}} / \mathrm{V}_{\mathrm{F}+1, \text { rated }}^{2} \\
& \mathrm{~B}_{\mathrm{L}}=\mathrm{Q}_{\mathrm{L}} / \mathrm{V}_{\mathrm{F}+1, \text { rated }}^{2} \text { and } \\
& \mathrm{V}_{\mathrm{F}+1, \text { rated }} \text { is the rated voltage at bus } \mathrm{F}+1 .
\end{aligned}
$$

Equation (1) can be represented in a matrix form as in (5), in which the first matrix is denoted as $\mathbf{Y}$ (called admittance matrix):

$$
\left|\begin{array}{cccccccc}
+\dot{Y}_{11} & -\dot{Y}_{12} & \ldots & -\dot{Y}_{I F} & \ldots & -\dot{Y}_{l i} & \ldots & -\dot{Y}_{I N} \\
\dot{Y}_{21} & +\dot{Y}_{22} & \ldots & +\dot{Y}_{2 F} & \ldots & -\dot{Y}_{2 i} & \ldots & -\dot{Y}_{2 N} \\
\ldots & \ldots & \ldots & \ldots & \ldots & \ldots & \ldots & \ldots \\
\dot{Y}_{F 1} & -\dot{Y}_{F 2} & \ldots & +\dot{Y}_{F F} & \ldots & -\dot{Y}_{F i} & \ldots & -\dot{Y}_{F N} \\
\ldots & \ldots & \ldots & \ldots & \ldots & \ldots & \ldots & \ldots \\
-\dot{Y}_{i 1} & -\dot{Y}_{i 2} & \ldots & -\dot{Y}_{i F} & \ldots & +\dot{Y}_{i i} & \ldots & -\dot{Y}_{i N} \\
\ldots & \ldots & \ldots & \ldots & \ldots & \ldots & \ldots & \ldots \\
\dot{Y}_{N 1} & -\dot{Y}_{N 2} & \ldots & -\dot{Y}_{N F} & \ldots & -\dot{Y}_{N i} & \ldots & +\dot{Y}_{N N}
\end{array}\right| \begin{gathered}
\dot{V}_{I} \\
\dot{V}_{2} \\
\ldots \\
\dot{V}_{F} \\
\ldots \\
\dot{V}_{i} \\
\ldots \\
\dot{V}_{N}
\end{gathered}|=| \begin{gathered}
\dot{J}_{l} \\
\dot{J}_{2} \\
\ldots \\
J_{F} \\
\ldots \\
J_{i} \\
\ldots \\
J_{N}
\end{gathered} \mid
$$

It is worth noting that when we need to assess voltage stability at a certain load bus, that bus is numbered $\mathrm{F}+1$ before forming either (1) or (5). Alternatively, at first, the equations are formed, then in order to consider any load bus $i$, rows $i$ and $\mathrm{F}+1$, and columns $i$ and $\mathrm{F}+1$ are exchanged. Based on the above analysis, we developped an algorithm for making a simplified equivalent diagram for the considered network, as in Figure 4.

\section{REPRESENTING UNCERTAIN FACTORS IN ELECTRICAL POWER SYSTEMS}

In a power system, random factors related to the load, failures of elements in the system, renewable energy sources can be represented by probability distribution functions [2729]. These functions describe the inherent nature of uncertainty factors and need to be integrated into the analysis of the system. In practice, such functions can be estimated based on historical data measured at loads, data on failures of lines, generating units, etc. In the literature load is usually expressed by a normal distribution function, while renewable power generation is usually represented by a generic function such as Beta, Gamma, Weibull functions, etc [29]. Random outage of an element such as transmission line, transformer, generating unit can be described by a $0-1$ distribution function (0: outage state, 1: working state; an operating element can be failed with a certain probability) [29]. If all generating units in a power plant are the same, the combination of 0-1 distribution function for each unit could be represented by a binomial distribution function [29].

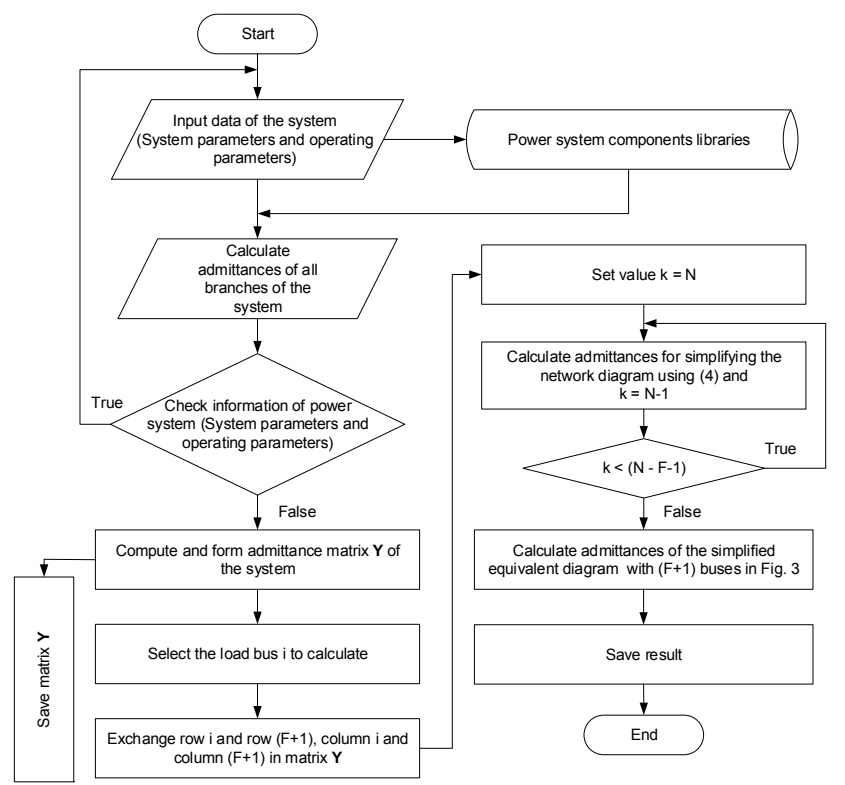

Fig. 4. Algorithm for making a simplified equivalent diagram based on Gaussian elimination method.

\section{STABILITY ASSESSING ALGORITHM DEVELOPMENT}

For an electrical power system with $\mathrm{N}$ buses (excluding a grounding bus, with $\mathrm{F}$ generation buses, bus 1 is considered as the slack bus), in order to examine the stability of the system according to the change at a certain load bus, first, we use the algorithm discussed in Section II to obtain the simplified equivalent diagram for the considered network. When the system is operating at a certain state with known network configuration, generating power, load, ect., we increase load at the considered bus and use the pragmatic criterion $\mathrm{dQ} / \mathrm{dV}$ presented in $[26,30]$ to construct the permissible operating region on a power plane under the conditions of a static stability limit as in Figure 5. In Figure 5, M1 is a certain operating point of the load considered belonging to stable region, while $\mathrm{M} 2$ belongs to unstable region of the system (see Figure 1). Suppose that the system is operating at M1, its stability and the dangerous level of increasing load can be evaluated according to the distance from M1 to the stability boundary. When random factors, as discussed in Section III, are considered, stability boundary is not represented by a single curve but by a set of curves as shown in Figure 6. Uncertainties in the system, related to load, renewable sources, random outages of lines, generating units, etc., can be represented by probability functions and set of random samples representing 
these functions can be generated using sampling techniques in statistics [31, 32]. In Figure 6, each curve is plotted for each sample. Assume that $\mathrm{N}_{1}$ samples are generated (i.e., $\mathrm{N}_{1}$ curves are plotted) and the considered load is operating at point M3 (see Figure 6). In order to evaluate dangerous level of the system in terms of static voltage stability, we draw a straight line connecting the origin $\mathrm{O}$ and $\mathrm{M} 3$ that intersects $\mathrm{N}_{2}$ curves and the probability of unstability (dangerous level) of the system can be calculated as in (6):

$$
p=\frac{\mathrm{N}_{2}}{\mathrm{~N}_{1}} 100[\%]
$$

Therefore, based on the operating point of the considered load on power plane, the stability of the system can be assessed and the system falls into one of three cases (corresponding to regions 1, 2, 3 on power plane): (1) if the load is working at point M1, the system is certainly stable $(p=0)$. (2) If it is working at $\mathrm{M} 2$, the system is certainly unstable $(p=100 \%)$. (3) If it is working at M3, the system may be stable or unstable with probability of instability $p(0 \%<p<100 \%)$. When $p$ is greatter than a certain value, the operator of the system needs to carry out appropriate remedial actions to reduce the load to avoid instability for the system. The proposed algorithm for assessing stability of power systems according to load changes considering uncertainty is shown in detail in Figure 7.

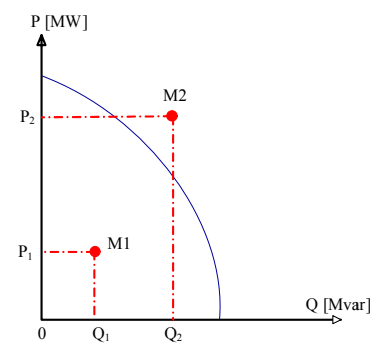

Fig. 5. Operating points on power plane.

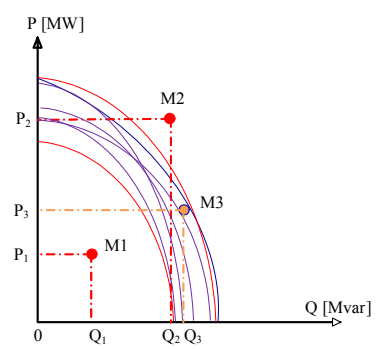

Fig. 6. Set of $\mathrm{P}-\mathrm{Q}$ curves on power plane when considering uncertainty in the system.

\section{MODELING AND RESULTS}

We consider the IEEE 39-bus system describded in [33] (Figure 8). In the system, load at each bus is modelled by a normal distribution characterized by its expected value (deterministic value [33]) and standard deviation (assumed to be equal to $10 \%$ of its expected value). Random outage of each branch is assumed to have probability of failure equal to $0.1 \%$.
Power plant connected to bus 1 is assumed to have 12 identical generating units, while remaining power plants include 10 identical generating units.
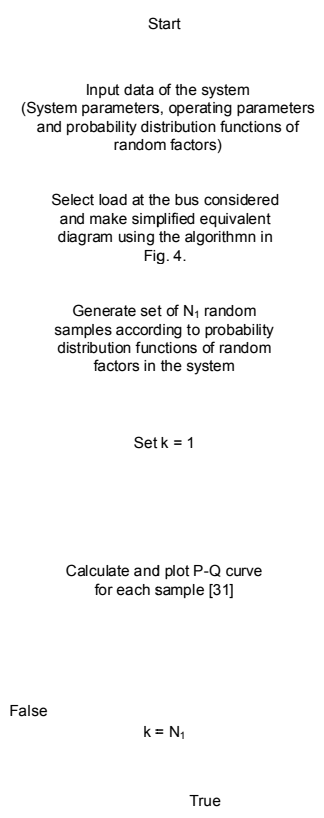

$\underset{\substack{\text { Save } \\ \text { result }}}{\text { s. }}$

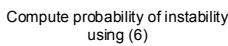

End

Fig. 7. Algorithm for assessing stability of power systems according to load changes considering uncertainty.

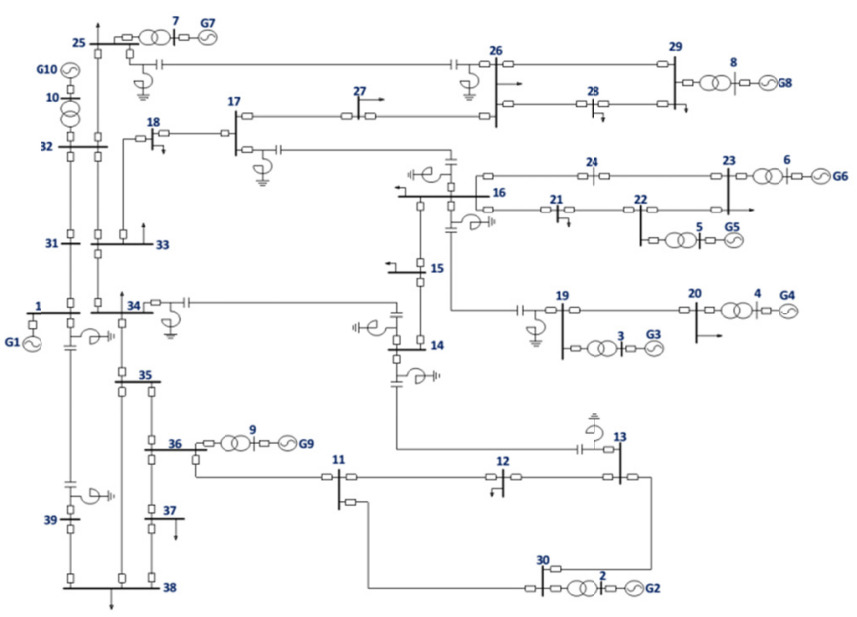

Fig. 8. Diagram of IEEE-39 bus system.

Probability of failure of each unit is assumed to be $8 \%$. Binomial and 0-1 distribution functions are used to represent uncertainties from generating units and branch outages. From those probability functions, 1000 samples are generated to represent uncertainties from random factors which are used for voltage stability assessment in this test. Based on the proposed 
algorithm, a computer program is developed to assess stability of IEEE 39-bus system according to load changes considering uncertainty using Delphi programming language. Starting the program, its interface is shown as in Figure 9.

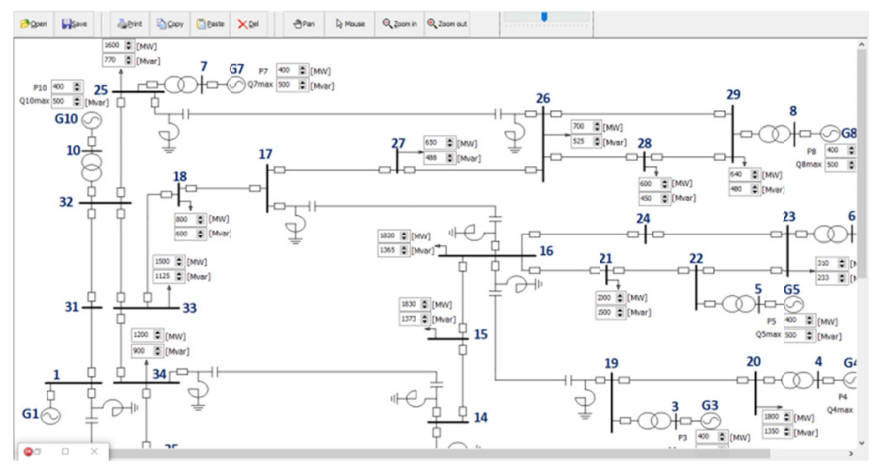

Fig. 9. Interface of the computer program developped for stability assessment of IEEE 39-bus system according to load changes.

When we need to evaluate the system according to conditions of static stability limit under uncertainty at a certain load bus, we right click on the bus. Figures from 10 to 12, for example, show the results of bus 25 corresponding to various bus operating conditions. In each Figure, a set of 1000 curves is plotted and these curves divide the power plane into different regions. Figures 10, 11 and 12 correspond to stable state (probability of instability of $0 \%$ ), unstable state (probability of instability of $100 \%$ ) and instability with probability equal to $30.4 \%$, respectively.

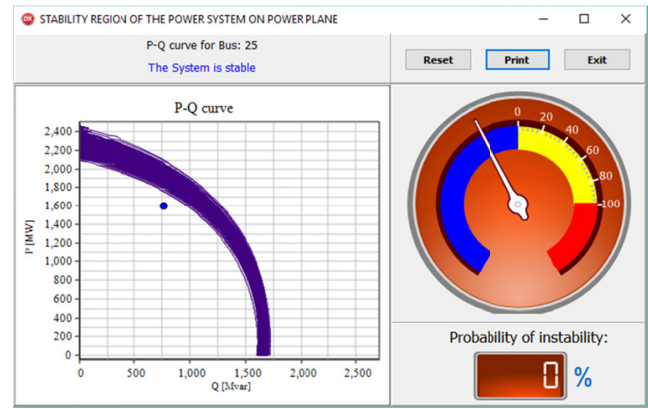

Fig. 10. Result of voltage stability assessment at bus 25 when the load is working at region 1 .

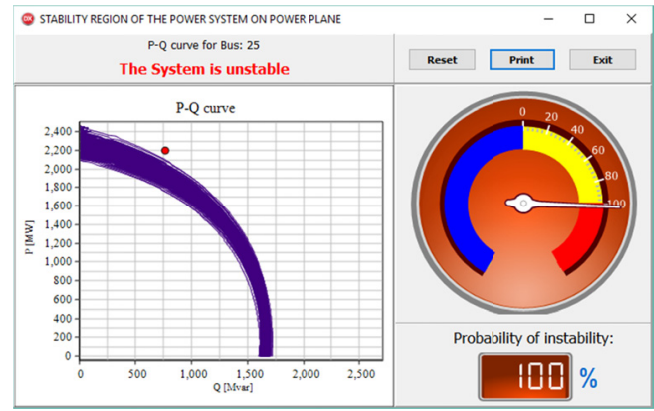

Fig. 11. Result of voltage stability assessment at bus 25 when the load is working at region 2 .

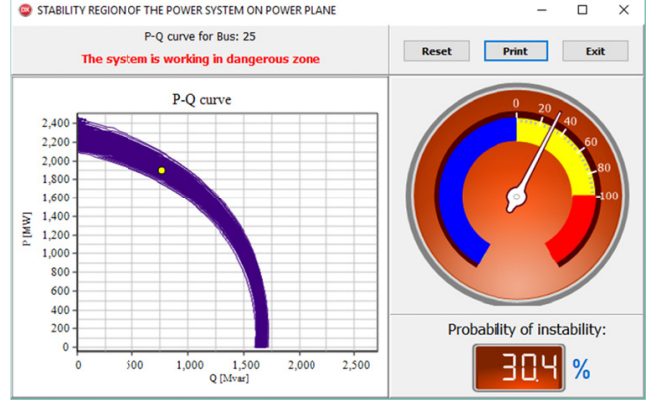

Fig. 12. Result of voltage stability assessment at bus 25 when the load is working at region 3 .

\section{CONCLUSIONS}

In this paper a methodology for voltage stability assessment under uncertainty is proposed. Random factors in a power system related to loads, random outages of elements in the system, renewable energy sources can be represented by probability distribution functions and taken into account in the assessment. The proposed approach can be used for online voltage stability study thanks to, adopting a technique for making a simplified equivalent diagram for a complex system based on Gaussian elimination method, and, making use of the analytical technique developed in [26] to plot P-Q curves. These techniques allow us to provide results quickly and can be applied to large-scale power systems for voltage stability assessment in real-time. Moreover, the P-Q curves constructed are realistic because no assumption on the change of load is used for their construction.

\section{References}

[1] P. Kundur, J. Paserba, V. Ajjarapu, G. Andersson, A. Bose, C. Canizares, N. Hatziargyriou, D. Hill, A. Stankovic, C. Taylor, T. Van Cutsem, V. Vittal, "Definition and classification of power system stability IEEE/CIGRE joint task force on stability terms and definitions", IEEE Transactions on Power Systems, Vol. 19, No. 3, pp. 1387-1401, 2004

[2] J. Hu, J. Cao, J. M. Guerrero, T. Yong, J. Yu, "Improving Frequency Stability Based on Distributed Control of Multiple Load Aggregators", IEEE Transactions on Smart Grid, Vol. 8, No. 4, pp. 1553-1567, 2017

[3] N. Nguyen, J. Mitra, "Reliability of Power System with High Wind Penetration Under Frequency Stability Constraint", IEEE Transactions on Power Systems, Vol. 33, No. 1, pp. 985-994, 2018

[4] N. Hatziargyriou, E. Karapidakis, D. Hatzifotis, "Frequency stability of power systems in large islands with wind power penetration", Bulk Power System Dynamics Control Symposium-IV, Restructuring, Vol. 102, 1998

[5] M. Oluic, M. Ghandhari, M. Berggren, "Methodology for Rotor Angle Transient Stability Assessment in Parameter Space”, IEEE Transactions on Power Systems, Vol. 32, No. 2, pp. 1202-1211, 2017

[6] L. Meegahapola, T. Littler, "Characterisation of large disturbance rotor angle and voltage stability in interconnected power networks with distributed wind generation", IET Renewable Power Generation, Vol. 9, No. 3, pp. 272-283, 2015

[7] E. Vittal, M. O’Malley, A Keane, "Rotor Angle Stability With High Penetrations of Wind Generation", IEEE Transactions on Power Systems, Vol. 27, No. 1, pp. 353-362, 2012

[8] C. W. Taylor, Power System Voltage Stability, McGraw-Hill Inc., 1994

[9] B. Leonardi, V. Ajjarapu, "Development of multilinear regression models for online voltage stability margin estimation", IEEE Transactions on Power Systems, Vol. 26, No. 1, pp. 374-383, 2011 
[10] D. Q. Zhou, U. D. Annakkage, A. D. Rajapakse, "Online monitoring of voltage stability margin using an artificial neural network", IEEE Transactions on Power Systems, Vol. 25, No. 3, pp. 1566-1574, 2010

[11] T. V. Cutsem, C. Vournas, Voltage Stability of Electric Power Systems, Springer, 1998

[12] J. A. de Leon, C. W. Taylor, "Understanding and solving shortterm voltage stability problems", IEEE PES Summer Meeting, Chicago, USA, pp. 745-752, July 21-25, 2002

[13] Y. Xu, R. Zhang, J. Zhao, Z. Y. Dong, D. Wang, H. Yang, K. P. Wong, "Assessing Short-Term Voltage Stability of Electric Power Systems by a Hierarchical Intelligent System", IEEE Transactions on Neural Networks and Learning Systems, Vol. 27, No. 8, pp. 1686-1696, 2016

[14] E. Vittal, M. O’Malley, A. Keane, "A steady-state voltage stability analysis of power systems with high penetrations of wind", IEEE Transactions on Power Systems, Vol. 25, No. 1, pp. 433-442, 2010

[15] H. K. Clark, New challenge: Voltage stability, IEEE Power Engineering Review, Vol. 19, pp. 30-37, 1990

[16] R. K. Gupta, Z. A. Alaywan, R. B. Stuart, T. A. Reece, "Steady state voltage instability operations perspective", IEEE Transactions on Power Systems, Vol. 5, No. 4, pp. 1345-1354, 1990

[17] M. H. Haque, "Determination of Steady-State Voltage Stability Limit Using P-Q Curves", IEEE Power Engineering Review, Vol. 22, pp. 7172,2002

[18] P. Kundur, Power System Stability and Control, McGraw-Hill Inc., 1994

[19] R. Toma, M. Gavrilas, "Voltage stability assessment for wind farms integration in electricity grids with and without consideration of voltage dependent loads", International Conference and Exposition on Electrical and Power Engineering (EPE 2016), Iasi, Romania, pp. 754-759, October 20-22, 2016

[20] M. S. Rawat, S. Vadhera, "Analysis of wind power penetration on power system voltage stability", IEEE 6th International Conference on Power Systems (ICPS), New Delhi, India, March 4-6, 2016

[21] V. Balamourougan, T. S. Sidhu, M. S. Sachdev, "Technique for online prediction of voltage collapse, IEE Proceedings - Generation, Transmission and Distribution, Vol. 151, No. 4, pp. 453-460, 2004

[22] T. V. Cutsem, C. Vournas, Voltage Stability of Electric Power Systems, Kluwer Academic, 1998

[23] M. Glavic, M. Lelic, D. Novosel, E. Heredia, D. Kosterev, “A Simple Computation and Visualization of Voltage Stability Power Margins in Real-Time", IEEE PES Transmission and Distribution Conference and Exposition (T\&D), Orlando, USA, May 7-10, 2012

[24] Y. Z. Lin, L. B. Shi, L. Z. Yao, Y. X. Ni, S. Y. Qin, R. M. Wang, J. P. Zhang, "An Analytical Solution for Voltage Stability Studies Incorporating Wind Power", Journal of Electrical Engineering and Technology, Vol. 10, No. 3, pp. 865-876, 2015

[25] P. Zhang, L. Min, J. Chen, Measurement Based Voltage Stability Monitoring and Control, U.S. Patent Application No. US 2009/0299664A1, 2009

[26] V. D. Ngo, D. D. Le, K. H. Le, V. K. Pham, A. Berizzi, "A Methodology for Determining Permissible Operating Region of Power Systems According to Conditions of Static Stability Limit", Energies, Vol. 10, No. 8, pp. 1-15, 2017

[27] G. J. Anders, Probability Concepts in Electric Power Systems, Wiley, 1990

[28] K. Krishnamoorthy, Handbook of Statistical Distributions with Applications, CRC Press, 2006

[29] D. D. Le, A. Berizzi, C. Bovo, "A probabilistic security assessment approach to power systems with integrated wind resources", Renewable Energy, Vol. 85, pp. 114-123, 2016

[30] J. Machowski, J. W. Bialek, J. R. Bumby, Power System Dynamics and Stability, John Wiley \& Sons Ltd., 1997

[31] J. E. Gentle, Random Number Generation and Monte Carlo Methods, Springer-Verlag, 2003

[32] G. Marsaglia, "Random Number Generation", in: A. Ralston, E. D. Reilly, Eds, Encyclopedia of Computer Science and Engineering, Van Nostrand Reinhold, pp. 1260-1264, 1983
[33] A. Dissanayaka, Risk Based Dynamic Security Assessment, Msc Thesis, University of Manitoba, 2010 